\title{
Dialogic Inquiry in Life Science Conversations of Family Groups in a Museum
}

\author{
Doris Ash \\ Education Department, 231 Crown College, 1156 High Street, \\ University of California-Santa Cruz, Santa Cruz, California 95964
}

\begin{abstract}
This research illustrates the efficacy of a new approach for collecting and analyzing family conversational data at museums and other informal settings. This article offers a detailed examination of a small data set (three families) that informs a larger body of work that focuses on conversation as methodology. The dialogic content of this work centers on biological themes, specifically adaptation. The biological principle becomes visible when families talk about survival strategies such as breeding or protection from predators. These themes arise from both the family members and the museum exhibit. This study also analyzes the inquiry skills families use as they make sense of science content. I assume that children and adults offer different interest areas or expertise for dialogic negotiation and that family members use inquiry skills in dialogue to explore matters of importance. This analysis offers educators methodological tools for investigating families' scientific sense-making in informal settings.
\end{abstract}

(c) 2003 Wiley Periodicals, Inc. J Res Sci Teach 40: 138-162, 2003

Museums are places where families play, talk, and learn from each other. Yet, although families make up more than half of all visitors to museums, we have little detailed understanding, beyond behavioral descriptions, of how family members interact with one another (Diamond, 1986; Ellenbogen, 2002; Hilke, 1987). In this research, I demonstrate a new methodological tool that allows a fine-grained analysis of collaborative scientific sense-making, based on family conversations. I call these conversations dialogic inquiry (Wells, 1999) because families use dialogue when they undertake mental and physical inquiry. In this article I focus specifically on two aspects of family dialogue: the thematic content that underpins conversations about life sciences and the inquiry process skills (Ash, 1999) that advance or hinder dialogue.

Looking at dialogue is not new to classroom research (Brown et al., 1993; Rosebery, Warren, \& Conant, 1992; Wells, 1999) but it is relatively new to informal learning research settings which, one can argue, offer a richer context and more free-choice learning opportunities (Falk \&

\footnotetext{
Contract grant sponsor: Museum Learning Collaborative, University of Pittsburgh, and Committee on Research Grant (COR) and Social Science Division, University of California, Santa Cruz.

Correspondence to: D. Ash; E-mail: dash5@cats.ucsc.edu

DOI 10.1002/tea.10069

Published online in Wiley InterScience (www.interscience.wiley.com).
} 
Dierking, 1992, 2000). The present work is informed, in part, by research carried out in classroom settings in Oakland, California (Brown, 1992; Brown et al., 1993; Brown \& Campione, 1996) in the Fostering a Community of Learners project (FCL), and also by Wells (2000) as part of the Developing Inquiring Communities in Education Project (DICEP) in Toronto, Canada.

In this work I adopt a Vygotskian (1978) sociocultural frame of reference that focuses on the zone of proximal development (zpd) as the interaction region between the family members, individually and collectively, and the exhibits. The Vygotskian perspective on the social origins of mind places an emphasis on the role of dialogue and the co-construction of knowledge, in our case between parents and children. This view presupposes that language is a negotiating medium for teaching and learning. Many others have prepared the way for this view. Halliday (1993) suggested that language is how experience becomes knowledge. Leont'ev (1981) called language a tool that "mediates activity and thus connects humans not only with the world of objects but also with other people" (p. 55). Vygotsky expressed this succinctly when he called language the tool of tools (1978).

My research emphasizes what Wells (1999) called the "co-construction of knowledge by more mature and less mature participants engaged in activity together" (p. xii). Wells (1999) suggested "education should be conducted as a dialogue about matters that are of interest and concern to the participants" (p. xi). This is the central feature of good classroom design (Brown, 1992) and arguably it is a central feature in informal settings as well, because dialogue functions as a way to carry out activities in which the participants are jointly involved (Brown et al., 1993; Vygotsky, 1978; Wells, 1997).

I have suggested previously that family dialogic inquiry occurs within a zpd established between the social ensemble, individually and collectively, and the actual or virtual artifacts that comprise exhibits (Ash, in press). Wells suggested that "the zpd may apply in any situation in which, while participating in an activity, individuals are in the process of developing mastery of practice or understanding of a topic" (Wells, 1999, p. 333). From FCL research, we know that learning environment design that encourages multiple overlapping zpds provides a variety of entry points into dialogue for learners of all ages and with distributed expertise (Brown et al., 1993). Ann Brown argued that in the classroom setting

\begin{abstract}
Theoretically we conceive of the community as composed of multiple zones of proximal development (Vygotsky, 1978), through which participants navigate via different routes and at different rates. A zone of proximal development is a learning region that learners can navigate with aid from a supporting context, including but not limited to people.... Because varieties of expertise and talent are encouraged, and there are multiple ways into the community (Lave \& Wenger), individual difference are legitimized (Heath, 1992). (Brown, Ellery, \& Campione, 1997, p. 12)
\end{abstract}

Because museums are rich sources of artifacts, people, gestures, and potential dialogic interactions (McManus, 1989, 1989; Paris \& Hapgood, in press), dialogic inquiry as instruction can take place at any particular exhibit as parents interact with their children, each other, and artifacts. Furthermore, we have observed that family groups (and others) split into dyads or triads at exhibits and then come together again later to share meaning. I take the view that multiple zpds are constructed because of the grouping and regrouping of the social ensemble at artifact-rich exhibits. Multiple zpds are also constructed as parents interact differentially with children in the same conversation. When these multiple routes are available, learners with different expertise, jointly or individually, can progress toward new levels of understanding using each other and exhibit materials as scaffold (Ash, in press; McManus, 1989). 


\section{Background Research}

\section{The Family in the Museum}

It has been suggested that museums are ideal locations to test out socioculturally framed research questions (Matusov \& Rogoff, 1995; Martin, 1996). By sociocultural I mean:

- There is a social group or ensemble (Granott, 1998) engaged in an activity. The ensemble can change throughout the activity (dyads, triads, etc.).

- The social group is engaged in a collaborative activity. This activity is informed by the individuals who comprise it; yet the activity reciprocally informs the individuals/ group.

- The social activity is mediated by tools, signs, people, symbols, and language, and by actions.

This sociocultural perspective differs from traditional child-directed, constructivist approach in museum learning research (Hein, 1998), which emphasizes the individual learner interacting and constructing meaning with phenomena; or if it includes a social aspect, the social group is seen as a collection of individuals, rather than as an interrelated, mutually constituting relationship (Rogoff, 1998). Rather, in the sociocultural view

The family works collectively to build a family perception of the communications from the museum.... These perceptions are inevitably mediated and adjusted by the social fiber of the family "forage, broadcast and comment" activity. (McManus, 1994, p. 91)

From past research, we know that family behaviors follow predictable patterns. We know that visitors have agendas "ranging from entertainment to convenience to family traditions"; that "these agendas directly influence what is learned during the museum visit"; and that "visitors do not distinguish between the worth of education and entertainment, [so that] both are effective motivations for learning" (Ellenbogen, 2000, p. 5). We know that parents teach and that family members exchange information across generations (Diamond, 1986). However, although past museum evaluation/research has focused on the family by designing exhibits and analyzing behaviors (Blud, 1990; Borun \& Dritsas, 1997; Diamond, 1986; Dierking, 1987; Hilke, 1987; McManus, 1994), there have been few detailed dialogic analyses of their interactions.

In closest alignment to the research described in this article is the work of Paulette McManus $(1988,1989,1994)$, who portrayed the basic museum family visit as "hunter-gatherer groups who actively forage in the museum to satisfy their curiosity about topics and objects that interest them, and to satisfy their curiosity about objects which museum professionals collect and study" (McManus, 1994, p. 91). She described family activity in terms of "Moves" family members make in relation to exhibit, text and each other- "the Move is concerned with getting things done in the social context ... Different moves have different structures" (McManus, 1988, p. 41).

According to McManus, as family members encounter interesting items they report back to the family group and broadcast their factual information to each other. The parents are likely to "identify and name the new items encountered by the children, and, in teaching mode, to comment on, or interpret, the information broadcast by the children much more than the children are likely to comment on the information broadcast by the parents" (McManus, 1994, p. 91). She argued that social experience is at the heart of the museum experience rather than peripheral, and that family members have agendas of their own in entering museums. Their interests are "brought to the museum" so that the "small scale situation which a visitor selects or finds himself in appears to 
have a profound influence on the way in which learning might be negotiated between designers and visitor" (McManus, 1989, pp. 43-44). This view is consistent with other work (Ash, in press), with the research presented here, and with research by Ellenbogen (personal communication, August 2001), who suggested that families groups hijack the agenda presented to them in museums, thus making it their own.

More recent museum learning research has begun to outline other characteristics of family conversations, such as the complexity of parent-assisted scientific reasoning interactions (Gleason \& Schauble, 2000), the role of parent-child explanation (Crowley \& Callanan, 1998; Crowley \& Galco, 1999), the categories of science content (Tunnicliffe, 1996), and the complex negotiation of thematic content (Ash, in press). A focus on the role of explanation promoted insights into the role of parental guidance. "Explanations are a privileged category of scientific discourse. At its core, science is a way of making sense of the world" (Crowley \& Galco, 1999, p. 407); yet most of the explanations they saw in museums were given by parents rather than actively requested by children.

Gleason and Schauble (2000) explored dyadic interaction while investigating the role of parents in offering guidance to children in the evidence-gathering and generation phase of shared scientific thinking. They suggest that "[whereas] parents also provided valuable assistance of many kinds ... they missed key opportunities for helping children interpret evidence, and as a result, children failed to achieve some of the gains in understanding that the parents did. The beliefs of parents and children did not come into closer alignment" (Gleason \& Schauble, 2000, p. 409).

Tunnicliffe (1996) looked closely at categories of biological content of social group conversations at museums, zoos, and botanical gardens, and made a quantitative analysis of the kinds of things children talk about as they visit live and preserved materials. Ash et al. (2000) discussed the role of thematic content in family conversations in many informal settings including aquariums, museums of science, and natural history museums. Ash (in press) suggested a mechanism for analyzing discourse in the museum setting using biological content as the focus.

Taken together, these past studies provide valuable background information but they also point to a need for more detailed examination of what families are actually saying to each other, and the specific disciplinary content and inquiry skills they bring to dialogue.

\section{Development of Children's Understanding of Science}

Adaptation, traits of life, and survival strategies of living things are thematic areas in the life sciences that have been important content areas for research in the classroom (Ash \& Brown, 1996) and in museum settings (Ash, in press). Both classroom and museum research work is based in part on a growing body of cognitive development research that clearly suggests that children's emergent biology has predictable foundations. In other words, we know the kinds of things the children find interesting about animals and plants.

Cognitive development research has described these roots of early biological understandings that young children bring to learning settings. These are the foundation of the themes children use as they visit museums. Susan Carey's (1985) definitive piece, Conceptual Change in Childhood, is centered on children's changing ideas about living things, be they person, animal, or plant. For example, until the age of 11 years children do not subsume plant into the category of living thing. Thus, living thing means something different to most children than to adults.

Children look at living things with a variety of expectations that inform their reasoning. Some researchers characterize children's early biological understanding as skeletal principles (R. Gelman, 1989), biases (Keil, 1992) or predispositions (S. Gelman \& Wellman, 1991). They argue 
that these early biological understandings help children organize the living world in essential ways. Young children are "predisposed to learn certain classes of information relevant to science, notably conceptions of physical and biological causality" (Brown et al., Ash, 1997, p. 14). "The idea is to understand children's emergent theories about biology and to lead them gradually toward deep principles, such as interdependence, biodiversity, adaptation and evolution" (Brown et al., 1997, p. 24). These early biological understandings include personification, essences, and functional reasoning. These three ways of reasoning are outlined below:

Personification. Personification is a form of person analogy in which children use the human as a referent for predicting the existence of certain characteristics in other living things. The closer the other living thing is to the human, the more closely the match will seem. For example, knowing that humans have spleens, children may predict that worms will not have spleens but that cats will. Using this reference system children can make projections with some accuracy (Carey, 1985).

Essences. This mode of reasoning includes the belief that there are certain fundamental essences that characterize living things (Medin \& Ortony, 1989), that nonliving things do not share. One cannot, for example, change a raccoon to a skunk by painting a stripe on its back. Living things tend to reproduce their own kind and have life cycles. If a thing moves of its own agency, it will have innards: that is, something inside that allows the movement (R. Gelman, 1990).

Functional Reasoning. Using functional reasoning or a design stance, children believe that structures on living things are built for a purpose: for example, sharp teeth are for cutting, long legs for running (Ash, 1995). These things are selectively important. For example, one does not ask what being transparent does for water, but children might well wonder about the purpose of a clear body for a jellyfish, firmly assuming that it has a purpose (Keil, 1992).

Early biological understandings interact with environmental information in flexible and not always accurate ways. However, they do provide a jumpstart on classifying, organizing, and understanding the living world.

We can assume that different family members know different things; i.e., knowledge is distributed in depth and topic. Distributed knowledge allows family members to develop multiple ways into biological dialogue using thematic areas of interest as the focus. These thematic areas can arise-from the individual: for example, "Mom, look at how big the frog's mouth is"; from the family as an ensemble: "Hey, this looks like the frog we used to have as a pet"; or from within the specific exhibit: for example, a sign might ask: "As you walk through these exhibits compare and contrast the size and shape of the mouths of these different frogs. What do you think they eat?" Individuals can share thematic interests according to their level of expertise or interest. Thus, ensemble members can have different developmental trajectories, different goals, and a different knowledge base.

Moreover, family members have different abilities to use the process skills of science. Although there is evidence that suggests that even young children can observe, predict, hypothesize, interpret, and synthesize (Brown et al., 1997), they are not often expected to use these skills. Most curricular material for younger children focuses on observing and questioning (Metz, 1995). Also, it is reasonable to expect that parents have more experience with process skills than their children, although parents may have had less experience interpreting evidence, synthesizing, or drawing conclusions in the scientific world (Gleason \& Schauble, 2000). Clearly domain- 
specific knowledge of the parents and children is important, as well as parents' understanding of how best to facilitate their children's understanding.

\section{Methods}

This study is part of a larger study of dialogic patterns in family conversations at several life science exhibits in California, including the Exploratorium, where this study was done, the California Academy of Sciences, the Monterey Bay Aquarium, and the Los Angeles County Museum of Natural History (Ash, in press; Ash, Ostrenko, Steier, \& Borun, 2000). The studies are uniform in their theoretical underpinnings and in key methodological features. This section includes information about the exhibition, research design, units of analysis, and analytic scheme.

\section{Exhibition Background}

The Frogs show at the Exploratorium - an interactive science museum in San Franciscowas designed to encourage visitors' exposure to thematic areas in science, especially adaptations of living things. The $3000-\mathrm{ft}^{2}$ show was a special exhibition featuring 75 live animals, experiential exhibits, and demonstrations. The Frogs exhibition was designed to explore:

the amazing diversity of these animals, the science behind what they do, and the richness of the human-frog relationship. The exhibition juxtaposed perceptions of frogs with scientific information about these strange and unusual creatures. The Frogs exhibition featured frogs and toads representing 20 different species from around the world as well as special exhibits on frog habitats, appetites, environmental adaptations, and vocal abilities. (Exploratorium press release, 1999)

\section{Data Collection}

Before this research project, a pilot study was done in which family and school groups were audiotaped while they moved naturally through the exhibition with no predetermined path. They were interviewed after the visit. This preliminary study helped determine that thematic material was available for family conversations, that free choice of exhibits was important, and that noise levels needed to be mitigated.

After this pilot phase, 3 families were solicited for in-depth visits to the exhibit: 2 were approached in museum settings, and 1 through professional colleagues. These families were selected on the basis of appropriate configuration (parents with children from ages 1-9 years), their availability, and their interest over time. All families chose their own path through all exhibits and were video and/or audiotaped for all conversations. The duration of visits was variable and interruptions were kept to a minimum. The family visits ranged from 43 minutes to 1 hour 25 minutes long. It was important that families felt their visit was natural and self-guided. Two forms of data were gathered, audio-recorded family conversations at and between exhibits, and pre- and postvisit family interviews. In the semistructured preinterview, families were asked about their museum-going patterns, their reasons for coming to museums, their goals or expectations for this visit, their interest in the life sciences, and about general areas of interest in the sciences. Typically the preinterview lasted 15-20 minutes. The postinterview was conducted immediately 
after the visit and consisted of feedback on the visit, particularly exhibits that interested them. They lasted 10-15 minutes. All data, conversational and interview, were transcribed.

Although most of the family dialogue in this study pertained directly the Frogs exhibition itself, just as on any other social occasion family members were free to talk about other topics that interested them.

\section{Representative Dialogic Segments}

Any conversation can be parsed into different segment sizes, based on any number of criteria. Segments can even be broken down into individual utterances or single words. Taken together, however, these words and segments comprise the museum visit. As segments can vary from a short sentence to an entire conversation, the selection criteria need to be explicit.

I have chosen an intermediate level of analysis (White, 1993) in which each segment provides just enough data to inform the reader about the participants, overall activity, types of mediation within the event, thematic content, and inquiry skills. These representative dialogic segments (RDSs) are typical of the larger conversation; every visit contains many such events. The explicit criteria for the selection of representative intermediate-size segments are as follows: (a) presence of thematic content and differential knowledge of these themes by family members, (b) use of inquiry skill and differential knowledge of these skills by family members, and (c) sustained dialogue in which members of the family attempt to make sense of the themes using inquiry skills.

I include the family in all of its subdivisions (dyads, triads, loners, etc.) during the museum visit, using Granott's definition of ensemble: "the smallest group of individuals who directly interact with one another during developmental processes related to a specific activity" (Granott, 1998, p. 1), along with the stipulation that "each individual's part gets its meaning when analyzed in relation to the whole" (Granott, 1998, p. 51). I assume that the size of the social group can change throughout the activity. The ensemble is a powerful analytic unit because it represents the fact that each individual is crucial to the final product but that the product itself is greater than the effort of any one individual.

Although there are many different ways to analyze discourse, for this project I have adopted a simple coding scheme that identifies the content theme and inquiry skill advanced by parent, child, or the exhibit in advancing understanding. This scheme allows the analyst to look closely at a selfcontained segment of conversation set within a larger activity. It allows each utterance to be analyzed separately and then to be linked to its segmental context. Thus, segments can be analyzed in isolation or collectively, but in this research, each RDS is situated within the larger social and cultural context.

The conventions used for analysis of RDSs are as follows: first identify the speaker and the utterance; then identify, in boxes underneath the utterance, the theme and process skill the utterance illustrates. Below the box listing the thematic area and process skill, there is another box that indicates whether the origin of the content theme is form/function reasoning, essences, or personification. Metacomments are included in boxes in the margin of the transcript; these comments reflect the relationship of the particular utterance to the overall dialogue. Metacomments include procedural comments as well as comments on how the utterance helps to moves the conversation forward or hinders it.

Figure 1 illustrates the coding protocol in more detail. The example begins with the particular utterance. In Figure 1, the mother says (after the boy has identified tadpoles): 


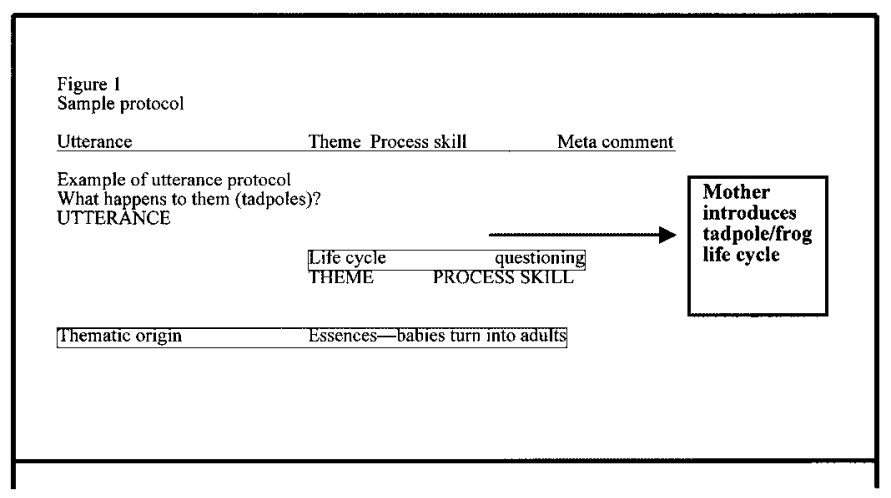

Figure 1. Sample protocol.

In this case the mother is talking about baby frogs and she has introduced the idea of the frog life cycle as a theme. Her question also demands an answer from the children. Thus, indicated in the long box directly below the utterance are two factors, biological theme and process skill, as seen below.

\begin{tabular}{lr|}
\hline Life cycle & questioning \\
\hline THEME & PROCESS SKILL
\end{tabular}

Below this is another box that suggests the origin of the thematic content. In this case the theme, life cycle, seems to arise from the notion of the essence of animals, especially that they live and they change. This is indicated as below.

Thematic origin $\quad$ Essences-babies turn into adults

To the right of the entire section there may be third box, a metabox, which attempts to situate the utterance within the larger context of the dialogue, as illustrated below.

\begin{tabular}{|l|}
\hline Mother \\
introduces \\
tadpole and \\
life cycle \\
\hline
\end{tabular}

\section{Results}

I selected three representative segments of conversations, one from each family. The first two families visited the same two exhibits, whereas the third family visited two different exhibits. These segments are typical of the three family conversations overall. On average, each family had between 5 and 8 RDSs per museum visit, interspersed with shorter dialogic episodes such as asking, initiating, naming, and responding, as suggested by McManus (1988).

The first RDS is analyzed in detail to provide a foundation for understanding the methodology; the second and third segments provide comparison and contrast to issues addressed in the first conversation. 


\section{RDS 1: Context}

The first conversation was among a family of four: mother, father, son (Age 6), and daughter (Age 4). The museum visit lasted approximately 43 minutes. The family did not regularly visit the Exploratorium but they did visit museums in the greater San Francisco Bay Area. In Hood's taxonomy they fit into the frequent museum-goers category although not as regularly as the other two families in this study.

In RDS 1, the family interacted with three different exhibits. The first was a large fresh-water tank with plants and tadpoles. The tank was the first piece of exhibitry visible from the bridge into the contained Frog exhibition area. It was situated low to the ground so that even young children could see into it. It was approximately $4 \mathrm{ft}$ long so that an entire family could view it simultaneously. It had information about frog development presented as drawings. The contiguous exhibit had a video that portrayed the frog life cycle in time lapse photography. There were also pictures of several different animals in the embryo state. Finally, the boy and the father visited a third exhibit with a brightly colored frog. Generally, the whole family moved together through the exhibits but they did split into dyads twice during this segment, once at the life cycle video and again at the colored frog. In both cases the boy and the father moved first to the new exhibits.

Thematic content was offered by the exhibit and by the parents and children. The son offered more than the daughter, who seemed shy and unfamiliar with the museum setting. She typically accompanied the mother while the son and father made a dyad. This is consistent with prior research (McManus, 1994; Diamond, 1985) in which parents often paired with children. In the interview, the parents indicated that they wanted the family to enjoy their visit together as a social event but also thought it important to learn together. At several points in the visit the father prompted the son to remember past information in a teacherlike way. The mother most often watched and responded to the children.

\section{RDS 1: Analysis (Figure 2)}

Overall, the two dominant themes of this segment are life cycle (especially in relation to babies and reproduction) of the frog and color as a source of protection from predators. These themes interweave seamlessly. The mother and the exhibit introduce the life cycle, whereas the son introduces the notion of color and protection. Other family members join the conversation as the daughter continues to look for various parts of the life cycle and as the father and mother elaborate and question the relationship between color and protection.

The girl says little but each utterance is about babies, thus reflecting the mother's original comments. Like any speaker, she selects a topic she knows something about and uses it consistently to enter the dialogue. It is a useful strategy. It is entirely normal at her age to be interested in babies and in growth and development (Rosengren, Gelman, Kalish, \& McCormick, 1991); even children as young as 3 years know that living things have babies and that they grow. Her interests and dialogue fit well within the context of essences described earlier in this report as an early and effective biological organizer for children's thinking.

The son is interested in color, its relationship to being poisonous, and the possible protection it affords. The father enthusiastically joins the son's theme of color as protection. Both parents talk with the boy and listen attentively. He is treated as an expert even though both parents are unsure of the accuracy of his comments. In the end the mother brings in countervailing evidence, but he seems not to believe this contradictory information. Again, his interest is consistent with cognitive development literature which suggests that children couple structure and function for living things. For this boy, frog color has a purpose. 
The mother is interested in the frog life cycle and relates it to the human life cycle, including her own birthing experiences. She maps frog characteristics to humans, and vice versa. Using personification, she compares and contrasts humans with other life forms, something neither of the children find particularly interesting, or perhaps are not able to understand. The father amplifies the mother's conversation by reading verbatim from signs.

Besides using thematic content, it is clear that the parents and children use inquiry skills such as observing, questioning, interpreting, comparing, and contrasting. There is little predicting, forming hypotheses, or synthesis. Interpretation occurs several times, when the parents help the children understand life cycles and the differences between frogs and humans. This differentiation would be difficult for the children without the parents' interpretation. This is complex material because the frog's discontinuous growth life cycle contrasts well with the more typical human life cycle of continuous growth. The parents' use of some but not all process skills, in particular observing and questioning, is typical of adult dialogue with young children by both teachers and parents.

Overall, the family interweaves different thematic areas, as each member remains with his or her theme. The parents amplify the children's interests as well as probe for accuracy. It is as if two conversations occur simultaneously with both parents acting as mediators. The father makes information available from exhibit signs. The mother mediates most often by asking questions or

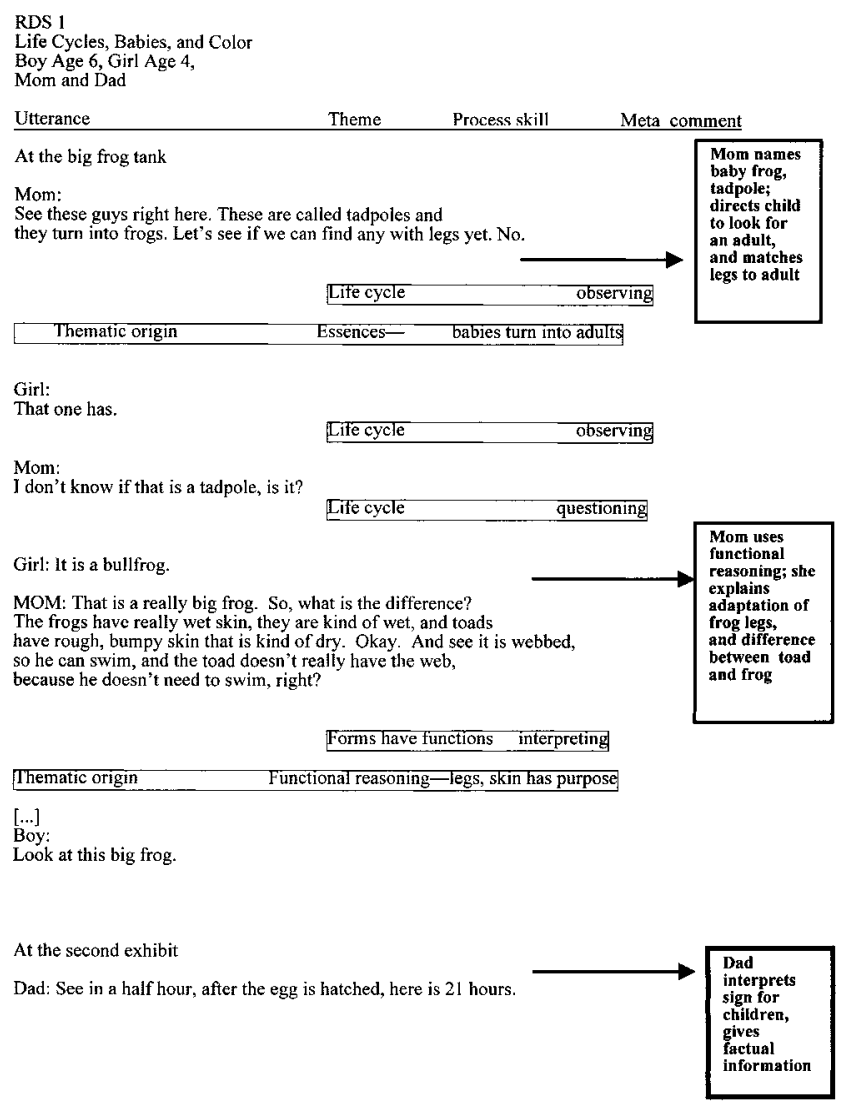

Figure 2. RDS 1. 


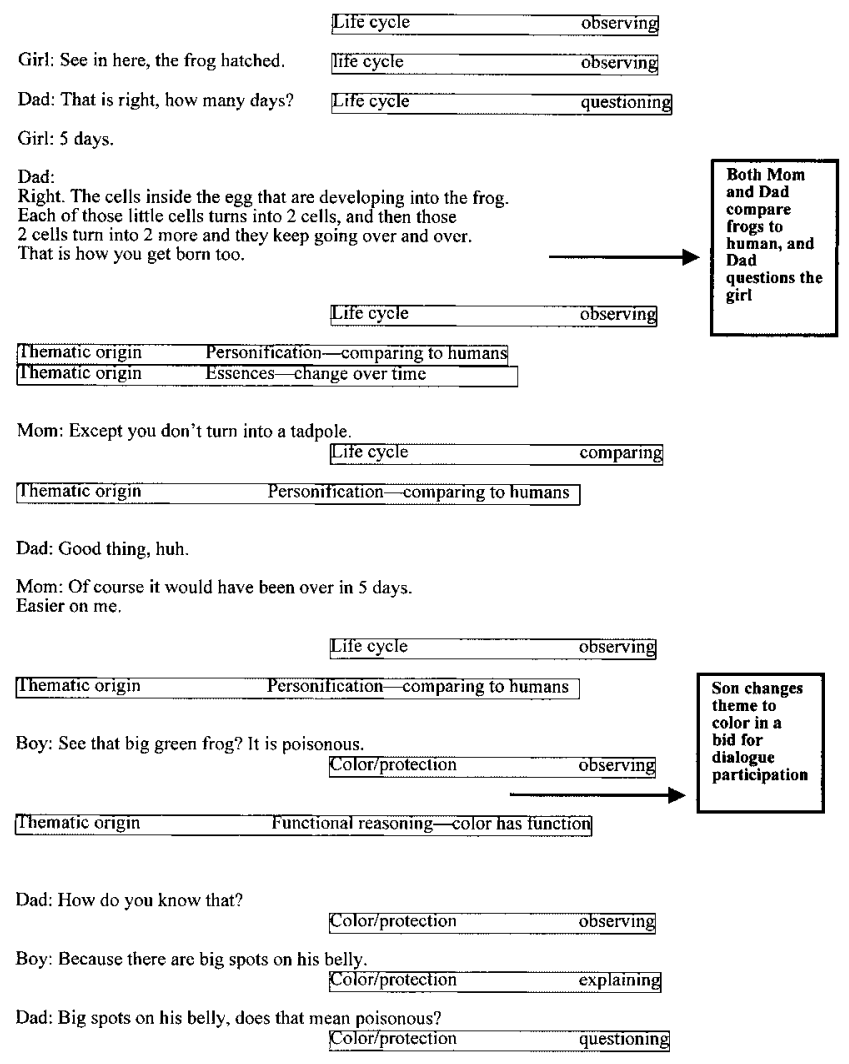

Figure 2. (Continued)

by interpreting important information. It is clear that the exhibit itself acts as the source of content, but that it is interpreted differently by each family member toward his or her own biological understanding. The family merges its agenda with the exhibit's (babies, color, protection, and life cycle) to integrate their dialogue seamlessly with the material presented to them.

This family's dialogic inquiry occurs across several overlapping zpds as family members group and regroup, share, and hold information given at different times by both children. For example, both parents help maintain themes individually for each of the children, but the children are not interested in each other's themes. Even though the exhibit encouraged the initial tadpole conversation by displaying them prominently, the direction of the conversation was determined by the family. Opportunities for education of family members occur repeatedly within several zpds as parents push for understanding, read signs, scaffold their children's understanding, and make comparisons between humans and frogs, individually and collectively.

\section{RDS 2 Context}

Family 2 consists of a mother and 2 children, a boy (Age 5) and a girl (Age 1.5). The girl is learning how to talk, yet she is an active participant. The mother came from a family with a long history of museum going and had herself frequented museums weekly. The mother's philosophy is to spend as much time as necessary on an exhibit and to revisit it regularly, while letting the children lead. The children had been to the Exploratorium regularly, as often as weekly, but had not seen the Frogs exhibition before. The mother has an educational agenda that included using 


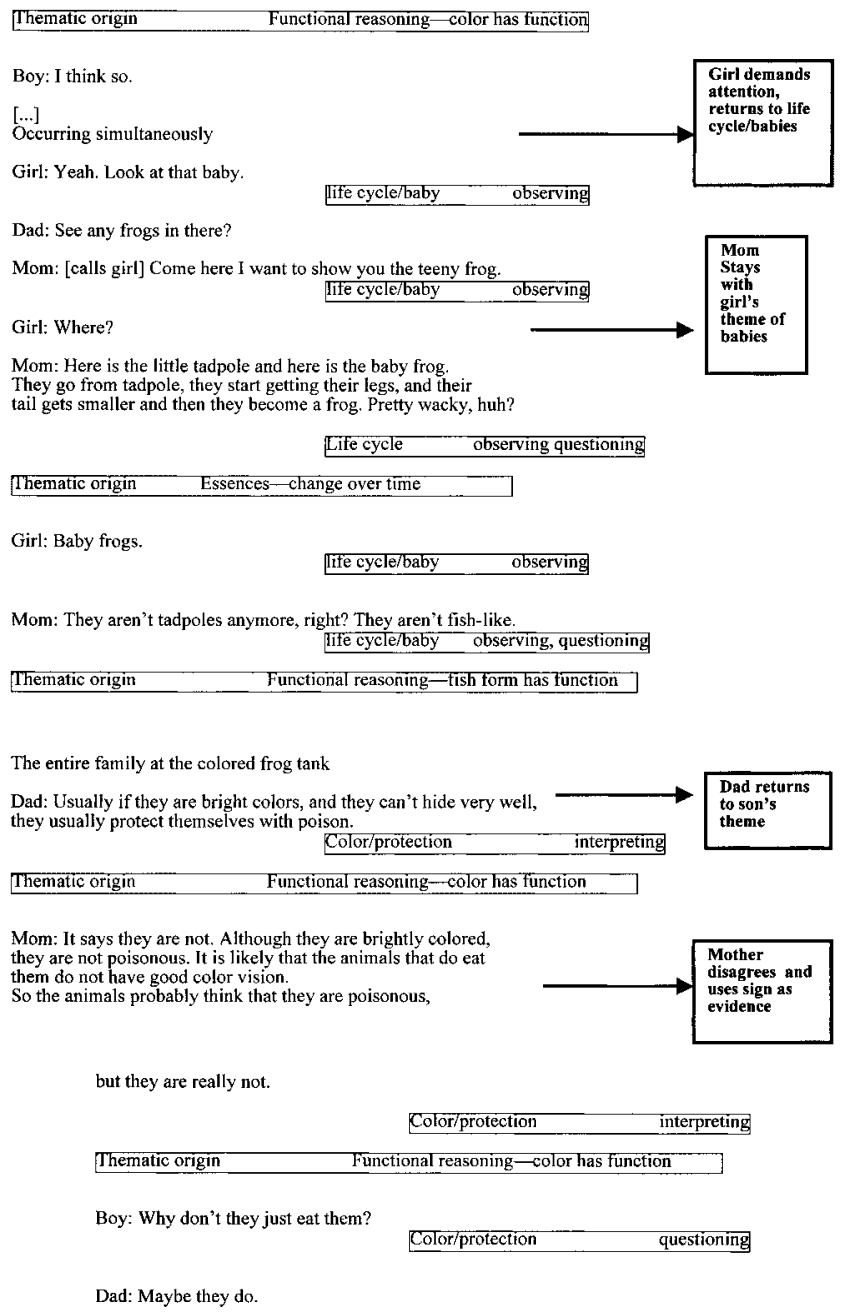

Figure 2. (Continued)

museums as learning environments for both children. For the younger daughter this included language socialization and practice.

In this segment, they are at the same large tank with tadpoles and frogs and the adjacent display that highlights frog development, as in RDS 1.

\section{RDS 2: Analysis (Figure 3)}

There is a great deal of active mediation by the mother, specifically using observing and questioning as inquiry skills. She uses these to keep the conversation moving and to expand the possible range of responses by the children. She makes frequent observations and links questions in complex ways, often addressing questions to both children at once, in running commentary that engages them with age-appropriate cues. Both children respond to her prompting.

The girl is learning to speak, and the mother encourages her by regularly inviting her into the conversation. With the boy, her attention is aimed at sharpening reasoning and observation skills, 


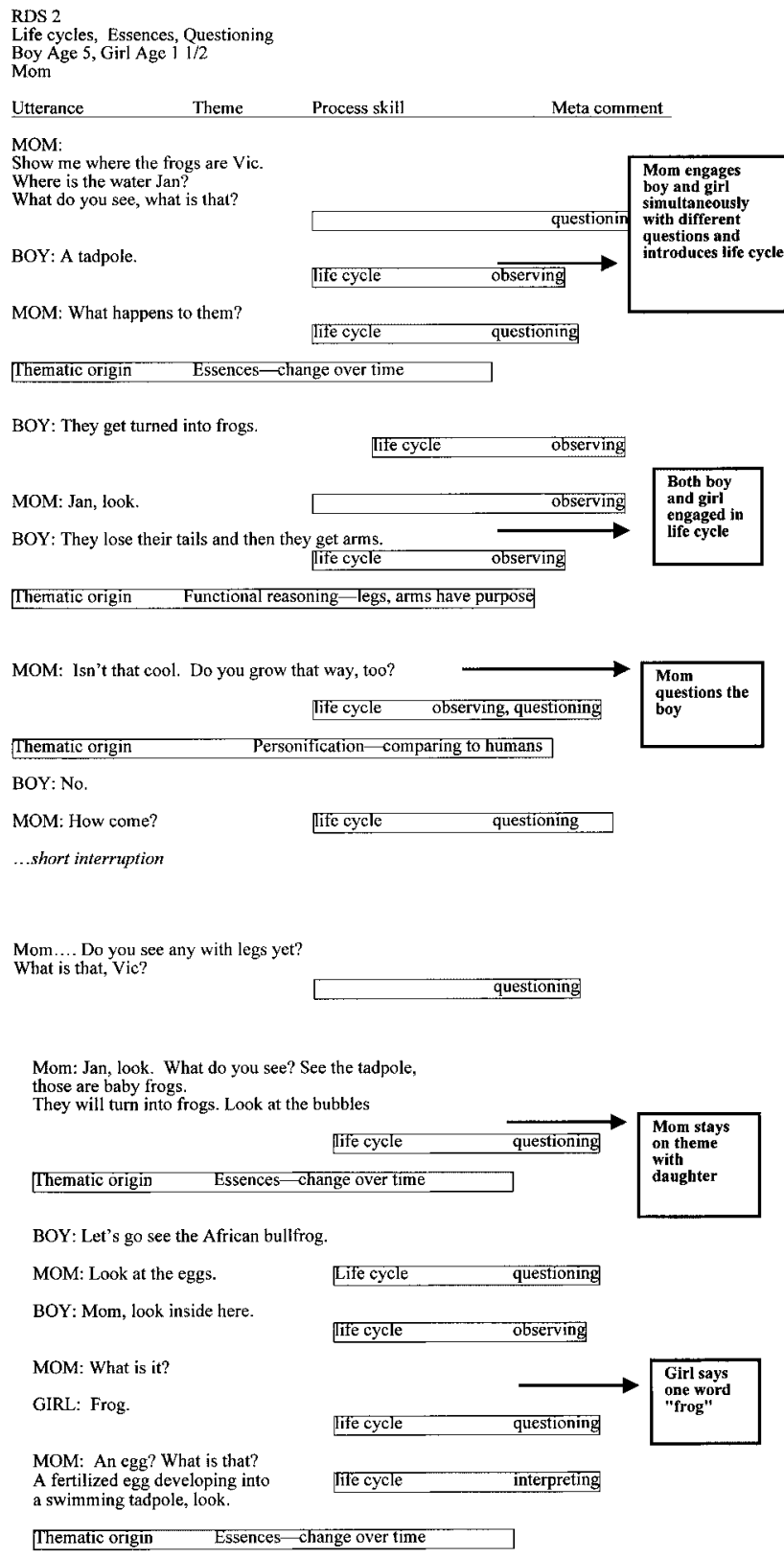

Figure 3. RDS 2.

as well as modeling how to get information from an exhibit. Her think-aloud style is a good example of how children can see reasoning modeled in a social context, perhaps enabling them to perform it similarly later.

Each of the mother's utterances requests the son's response, if only an acknowledgment that he has heard her request. Over half the utterances in the chosen segment illustrate questioning as 
the inquiry skill. Even when the boy wants to move on, saying "Let's see the bullfrog," she continues to prompt with: "Look at the eggs." This works; the boy reengages with the material. Right after this, the girl says the word frog, her only word during the entire segment.

Thematically, the mother focuses on life cycles. The boy responds like the younger girl in the previous segment. Some of the phrases used by the two families are nearly identical. For example, when both mothers talk about tadpoles, they say, "They grow up into frogs." Embedded in this statement are several important subthemes: living things grow up, they change, and in this case they grow up to look like something different from themselves. When faced with an unusual life cycle, learners focus on the stages of the life cycle, and by implication compare it with humans. Based on Conversations 1 and 2, one expected follow-up to an illustration of the frog life cycle would be explanations of the difference between frog and human growth patterns.

This family also brings a content agenda to its dialogue. Whereas the mothers in RDS 1 and 2 may talk about the same thematic material with similar prompts, the overarching agenda is different in the two families. The mother in RDS 2 actively pushes for knowledge building with questions, whereas the mother in RDS 1 waits for it to emerge. Mother 2 actively facilitates language use by her daughter, whereas Mother 1 follows her daughter's lead and then offers new information. Thus, we find different goals, similar themes, and different uses of mediation skills in RDS 1 and 2. This implies that even when families seem to be doing the same things, they may have different agendas as they opportunistically use the museum for their own ends.

As with Family 1, this dialogue seems to occur across multiple zpds as the mother is able to interact individually and jointly with the two children, at once scaffolding the young daughter's language development and almost simultaneously questioning her son abut his biological reasoning.

\section{RDS 3 Context}

The third family consists of a mother, father, and two young sons, aged 6 and 8 years. They are frequent museum goers, although not as frequent as Family 2 . They regularly visit a variety of locations, including zoos and aquariums in and around California. The mother is an artist; the father is an engineer. The family seems accustomed to talking together in a variety of configurations. The mother wants the family to have an enjoyable social outing together. The boys have different areas of interest with regard to science. The older son is more comfortable with the physical sciences and the younger with life sciences.

Their conversation takes place at a different area in the same Frog exhibition, again across two different exhibits. One exhibit contains the skeleton of a frog in a case; next to it is a human-size silhouette of a body with the frog on one half and a human on the other. There is a direct mapping of organs from one to the other. The exhibit design highlights similarities and differences between humans and frogs.

\section{Analysis: RDS 3 (Figure 4)}

This third conversation occurs between the adults, as the children listen. The boys say only two things. The skeleton of the frog evokes a strong response in the mother as she connects the exhibit with her past experience in a storytelling fashion. In an almost dreamy voice she tells her sons and her husband of her own experiences with frogs and how the dissection experience has colored her life. In her mind, she smells the formaldehyde and tells the family about her own past. Her husband is supportive but more interested in the form and structure of the frogs and in the comparison with humans. The boys listen. 


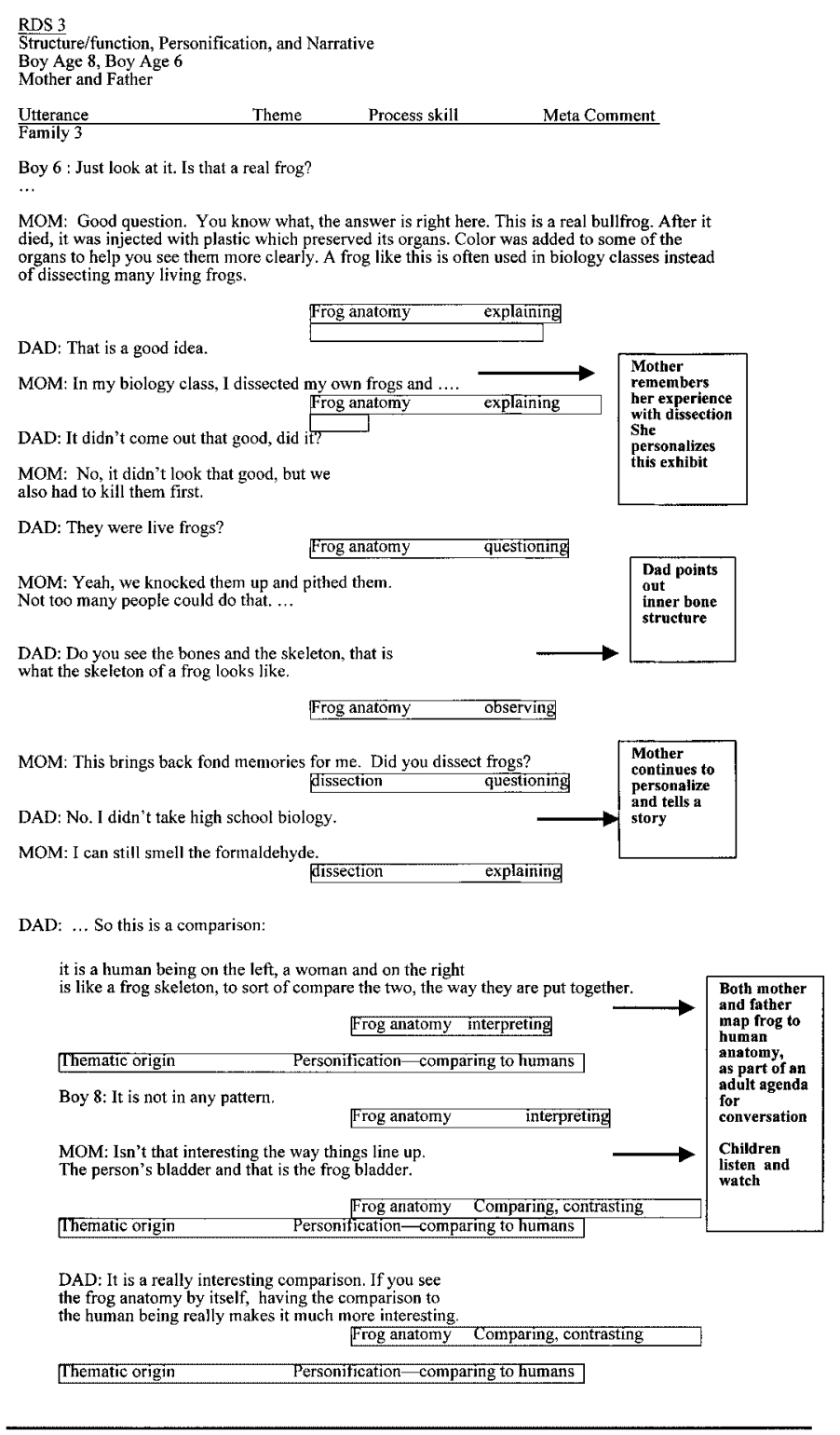

Figure 4. RDS 3.

The parents in RDS 3 are both fascinated by the mapping of organs from frog to human (personification), echoing the interest of the first family, but this time with an anatomical rather than life cycle focus. Again, the children seem less interested in this comparison; note that the older son does not see a pattern. The parents may think it is self-evident that there are visible parallel structures, whereas the children miss that insight perhaps because developmentally they do not yet expect those parallels or appreciate their importance in relation to evolution.

The focus of the conversation in RDS 3 is on thematic material (form, structure, and personification), as in both of the other segments. This time, however, thematic material is used as 
the basis of a narrative rather than questioning or directly guiding children's thinking in some other way. Thus, whereas the material of the discussion may seem similar to that of the first two conversations, the conversational mode of narration is different. This third mother adapts the museum exhibit material for her own broader relational agenda-an opportunity to relive experiences, connect with the past, and, more important, tell her sons about her own history as an artist and biologist.

The adults in this family appear comfortable with focusing on their own interests and their relationship with one another rather than attending only to the children. This may lead to different cognitive and social learning for these children and might be a valuable focus for future research within this theoretical and methodological framework.

Finally, as with Families 1 and 2, there appear to be several zpds in this dialogue, even though the children are less active dialogically. There is a dual agenda as the mother refers back to her history and the father is compelled by the structure-function relationships. These two dialogic activities occur in tandem, interacting on occasion.

\section{Discussion}

The goal of this research is twofold. The first is to use a Vygotskian interpretation, specifically the zone of proximal development, to design a new method for analyzing family dialogue as it occurs naturally in museums. Second, I have tested this method with a small data set, focusing on specific aspects of dialogic inquiry. In this discussion, I address, in order, the units of analysis chosen, thematic content, inquiry skills, a model for dialogic inquiry in multiple zpds, and, last, the limitations of this kind of research.

\section{Units of Analysis}

A flexible unit of analysis for thr family group reflects the way families actually hunt, gather, and talk about museum content. In this study, all three family groups remained together part of the time and separated part of the time as they made their way through exhibits. A flexible unit of analysis for the exhibition area enables us to track how families actually carry themes across exhibits and how they make use of exhibit content according to their own knowledge base. This requires data collection to span several exhibits within an exhibition.

The RDSs, as a unit of discourse analysis, have captured the complex negotiating processes that comprise the family museum visit. The understanding that members achieved was a product of several factors including the family thematic agenda, the museum's thematic agenda, and the inquiry skills used to talk about them. Each of the three RDSs allowed us to identify and characterize patterns as they emerged within each family. For example, we saw that whereas the mother in Family 2 used many questions, the mother in Family 3 used a reflective narrative and the mother in Family 1 used steady parental scaffolding as discourse themes emerged from the children.

Finally, although patterns of museum dialogue may seem unique to each family, they are not entirely idiosyncratic. From the more detailed RDS analyses, we can note, for example, functional similarities in how families use content themes to make sense of exhibits.

\section{Thematic Dialogic Content}

This study supports the hypothesis that families use biological themes as entry points to conversational meaning making at exhibits designed around life science content. Family members 
in this study used thematic content to their own ends- to negotiate meaning, get attention, push on reasoning skills, advance language acquisition and tell personal stories over time and context. In these RDSs, family members brought up themes individually or collectively, appropriated each other's thematic materials, and cooperated to achieve common understanding.

For Families 1 and 2, the content centered on children's understanding of life cycle and color as protection. For Family 3, the frog was a metaphor for life experience, one that the father and mother did not share equally with each other as an experience but did share as dialogue. The themes in RDSs 1 and 2 were predictable and similar given the exhibit content - frog life cycleyet they were advanced differently by adults and children within the two families.

The thematic content was consistent with the findings of cognitive development research. Young children talked about the essence of animals: for example, that they reproduce themselves and that they have life cycles. Adults used personification and mapped human characteristics to other species. Children did not use personification as much as adults.

Inagaki and Sugiyama's (1988) research suggests that for 4- to 5-year-olds, only about $50 \%$ of the properties of an animal, such as the (phylogenetically distant) frog, would be projected onto humans. Perhaps young children do not perceive frogs as closely related to humans, whereas the parents might think this is self-evident. Adults would reason that because humans and frogs are both vertebrates, there are considerable areas for overlap of internal organs. This may be different for young children who have no clear idea of internal organs, except that they exist. This does not mean, however, that children do not expect animals such as frogs to grow; they do (Rosengren et al., 1991). Even young children have some understanding of natural life cycles. However, they may not attribute these as easily to phylogentically distant organisms such as the frog, even though they do "apply the same expectations across a wide range of species" (Rosengren et al., 1991, p. 318).

Similarly, both parents and children expected structures to have function; for example, frogs and toads have different kinds of feet for different purposes. Functional reasoning allows children (and adults) to look at structures as if they were designed for functional purposes and to wonder about the design problems they might solve (Ash, 1995; Keil, 1992). Over time, generalizations regarding these structure-function relationships can lead to larger discussions about adaptation (Ash, in press; Ash, 1995, Ash \& Brown, 1996).

Content themes can have a profound impact on family dialogue. Take, for example, the notion of life cycles. Even if children understand that things grow, they may not understand that there are different patterns of growth. In human growth, the baby looks like the parent and continues to get bigger. The frog growth cycle is quite different, however, as the baby does not look like the adult. It takes some explaining to make the connection between frog and tadpole. The frog is an invaluable teaching tool because it is an exception to the more basic growth pattern we know as humans. Both Families 1 and 2 used the frog life cycle and made comparisons with humans.

In RDS 1, the mother says earlier to the girl and boy:

Except you don't turn into a tadpole.

Later she says to the girl:

They go from tadpole, they start getting their legs, and their tail gets smaller and then they become a frog. Pretty wacky, huh?

Later she says:

They aren't tadpoles anymore, right? They aren't fishlike. 
In this case, the mother explains the tadpole to frog life cycle using exception to the rule reasoning. All things grow into adults so that they can have babies-continuation and preservation of the species - the prime directive of evolution. This is something most adults take for granted, but one that children may need to witness in many different ways to understand it fully. The frog does this in a "wacky way." However, it does the same thing that humans do: hatch (birth), grow, become adult, and make more babies.

In RDS 2, after the boy identifies tadpoles, the mother asks:

What happens to them?

The boy responds by saying:

They turn into frogs.

The mother asks directly:

Do you grow that way, too (like a tadpole)?

This mother directly asks the son if humans are the same as frogs in their growth. Although this is a different prompt from the one used by Family 1, the underlying issue is the same: What happens to the tadpole and why is it different from humans?

Parents and children have different interests and concerns; children might be concerned with alive compared with dead (or real), for instance (Carey, 1985), whereas parents, knowing taxonomy, may wish to understand the place of a species in classification schemes. Yet, even when parents have different content understanding, their basic use of thematic materials overlaps their children's in important ways. For example, in RDS 3, while the children are grappling with the concept real in relation to the skeleton of a frog, the parents used that question as a springboard to explain how humans and frogs are similar.

\section{Inquiry Skills}

Parents actively choose and model inquiry skills that enhance or detract from thematic content. Parents affect a child's level of active participation by recognizing and responding to the children's dialogic turns or by ignoring them, as in the typical classroom initiate-responsefollow-up (IRF): teacher initiates; student responds, and teacher follows up (Wells, 1999). This pattern is seen, for example, in RDS 2:

Mom: Show me where the frogs are, Vic. Where is the water, Jan? What do you see, what is that?

Boy: A tadpole.

Mom: What happens to them?

In this case, the mother follows up the child's response with another question, a move that encourages the conversation to continue rather than stop. This mother is recognizing, responding, and keeping the conversation open. Moreover, any person or object can act as a stimulus for further conversation; for example, even the 1.5-year-old, by uttering the single word "Frog," subsequently touched off a flurry of verbal cues from the mother. 
In these RDSs, parents engaged and guided conversation explicitly by using inquiry skills such as questioning. When parents wanted to know more about the child's ideas, they asked them to observe more closely or used questions to elicit their thinking. For example, in RDS 1 the father asks the son about his knowledge of color.

Boy: See that big green frog? It is poisonous.

Dad: How do you know that?

Boy: Because there are big spots on his belly.

It is clear from these RDSs that parents used a variety of inquiry skills such as observing, questioning, hypothesizing, explaining, and interpreting as they talked to their children. In Gleason and Schauble (2000), parents were good at guiding their children's understanding in some skills-for example, in obtaining and planning evidence-but weak in helping children to interpret the evidence to draw conclusions. Their results suggest that perhaps "adults may assume that children's understanding is the same as theirs" so that if "an experimental outcome is observed by both, there is not need for discussion" (Gleason \& Schauble, 2000, p. 45). Parents may assume that their children understand events as they do, or that science is just a matter of "looking and seeing" (Driver, Leach, Millar, \& Scott, 1996).

\section{Multiple zpds and Dialogic Inquiry}

Vygotsky suggested "that instruction is maximally productive when it occurs at certain points in the zone of proximal development" (1987, p. 212). In these RDSs, parents and children have unequal practice using thematic content and inquiry skills, so that each brings diverse interests to museum dialogue. Coupled with this, the museum provides selected artifacts and signage that interact with parents' and children's distributed expertise. Difference demands talk, explanation, questions, and negotiation. These conditions are ideal instructional opportunities in the sense that Vygotsky suggested. In fact, the kind of difference that is normal within family interactions at museums is exactly the kind that is carefully designed and engineered in the Fostering a Community of Learners (FCL) classroom. "The zone of proximal development is created in the interaction between the student and the co-participants in an activity, including the available tools and the selected practices and depends on the nature and quality of that interaction as much as on the upper boundary of the learner's capability" (Wells, 1999, p. 318). We can say, based on the analysis of these RDSs, that learning and teaching set within multiple zpds rely on the dialogic social interaction (Brown et al., 1993; Wells, 1999) that occurs as parents and children attempt to negotiate meaning while using available material in formal or informal educational settings. I have used these three RDSs to illustrate this point.

These RDS, although limited in number and size, offer a range of possibilities. Whereas each family offered distinct ways to interact dialogically, taken together the three RDSs provide a beginning taxonomy of the kinds of family dialogic interactions possible with multiple zpds. There were multiple entry points to active participation in the RDSs as each family moved toward some common understanding in distinct yet predictable ways. The three made sense by practicing particular inquiry skills and by offering particular content themes to the dialogues, and these in turn influenced the levels of meaning achieved by each family. Parental dialogic styles varied from narrative history (Family 3) to active questioning of information in an IRF format (Family 2), and or by allowing children's interests to come to the fore and following them where they led. Some families used all three of these modes depending on the content. 
In each of the RDSs, there was a dynamic interaction between members and the exhibit, and with each utterance the meaning changed slightly so that the co-constructed meaning was not apparent until the end of the particular sequence. Vygotsky (1978) argued that higher mental functions have social origins that are first expressed between individuals before they are internalized within the individual. In this family learning setting, it appears that both parents and children rehearsed verbally before internalizing privately. The internalization is actively learned with modeling by more experienced parents, peers, or text (Wertsch, 1998). In this study the modeling comes from adults and the exhibits. Although many different models of social activity within the zpd are available (Martin, 1995; Wells, 2000) I have developed the model outlined in Figure 5.

In Figure 5 I capture the activities that occur within a joint zpd as each person or artifact contributes according to the current level of expertise. The three boxes are meant to illustrate these three intertwined aspects of dialogic inquiry - the biological themes that the parents and children offer, the themes that the exhibit or museum offers, and the negotiating strategies used by the parents, children, or exhibit itself. All three are situated within mutually created zones of proximal development that change as the participants change. Figure 5 indicates the interplay among these three factors.

In the sample RDSs, the ongoing dialogue between family and exhibit illustrates many examples of this interplay of themes and strategies (skills). For example, in RDS 1, the boy offered the hypothesis that bright frog color meant it was poisonous, and his ideas were left unchallenged until subsequent information was made available to question his original statement. In this case, the parents clearly heard and held his concept as part of ideas to be revisited when (or if) more information became available, in this case, from the exhibit signage. As in real life situations, information became available over time, and thus the conversation had an ebb and flow in which ambiguity or contradictory information could be tolerated for shorter or longer prods of time.

From this and other research (Ash, in press; Ellengbogen, in press; McManus, 1994) it seems clear that the family agenda interacts with the museum agenda. There is reciprocity among individual, group, and museum themes and the strategies used to advance them. Individuals hold information, revisit it, challenge it, and offer it at opportunistic moments. Exhibit designers might

Dialogic Inquiry in the zone of proximal development

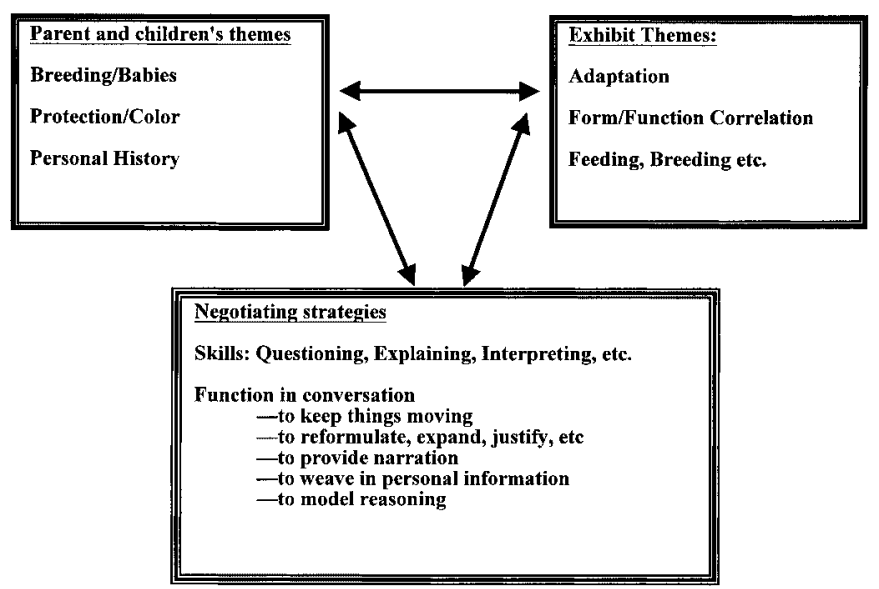

Figure 5. Dialogic inquiry into the zone of proximal development. 
expect understanding to arise from within a single exhibit; instead, in these RDSs families collected complex information across exhibits and over time. They also identified and weighed the role of the speaker as well as the reasonableness of the argument. For example, in RDS 1 it was reasonable for the boy to expect color and pigmentation to support protection, but in the case of this particular frog that expectation proved incorrect.

\section{Limitations}

Finally, I address two limitations of this study: First, there is the issue of verifying with family participants the meaning of their conversations, and, second, the small size of the data set in making generalizations is problematic.

First, it seems important to revisit with participants their ideas, agendas, and thinking at the time of their visit. In their study, using the video trace technique, Stevens and Hall (1997) used immediate video-based postinterviews with participants. Although this technique was not used in this research, an adaptation is now being put into practice. The same families who took part in this study, and who are part of a longitudinal study of family museum learning, view portions of the video of their visit as I interview family members about their thinking and actions at particular exhibits. These stimulated recall techniques are meant to augment the researcher's interpretation and family recall of important information from visits after the fact. These data are not yet available for publication.

Second, there is the issue of generalizability or how representative a small data set can be to the larger field of museum learning. The main goal of this study was to present a viable alternative method for collecting and analysing dialogic data in informal settings using a Vygotskian theoretical foundation. I have accomplished this goal. Although I make no claim to the representativeness of three dialogic segments, I do suggest that this method and theoretical framework can be used for a variety of research aims.

This view of dialogic inquiry research fits well with the larger research perspective (Brown et al., 1993; Gallas, 1995; Leinhardt, Crowley, \& Knudson, in press; Lemke, 1990; Wells, 1999) that focuses on analysis of scientific dialogue as a research method in classrooms. In this study I have expanded this framework to the field of museum learning. By doing so I (and others) can gather larger data sets, following the same or related methodology, and make comparison studies between classroom and museum settings.

\section{Conclusion}

Sociocultural theory focuses attention on language as the mediator of interactions; thus, dialogic inquiry is a valuable focus for analysis. In this work, by deliberately analyzing discourse in its raw state, I demonstrate that RDSs are flexible units of analysis that reflect larger patterns of interaction. RDSs allow for analyzing co-construction of meaning over time and across contexts. The RDS can therefore provide a data set for interpretation by scientists, educators, and exhibit designers. RDSs occur within multiple zones of proximal development.

There are important implications for this work. According to Hein (1998), "the application of these [sociocultural] ideas to research on how people learn in museums is only recently bearing fruit" (p. 149). I argue that the first way in which sociocultural theory affects our understanding of the family museum visit is by guiding our choice of units and levels of analysis. We need refined methods as well as hypothesis-generating research with rich descriptions of people interacting with museums (Martin, 1996). 
Family dialogues reflect individual and collective thematic agendas, the exhibit or museum agenda, and the specific skills that move conversations forward or hinder them. The complex interaction of content and negotiating strategies has only begun to be made visible and explicit. Much work needs to be done to advance our rudimentary understanding. Clearly, the museum is not a static entity to be experienced passively, but is rather the result of a negotiation between the visitors and the museum.

This work is based in part on a paper presented at the National Association for Research in Science Teaching, New Orleans, 2000. This research was funded in part by the Museum Learning Collaborative.

\section{References}

Ash, D. (1995). From functional reasoning to an adaptationist stance: Children's transition toward deep biology. Unpublished thesis, University of California, Berkeley.

Ash, D. (1999). The process skills of inquiry. In: Inquiry in the K-5 classroom: Foundations (Vol. 2, pp. 51-62). Washington, DC: National Science Foundation.

Ash, D. (2002). Negotiation of 1 thematic conversations about biology. In Leinhardt G., Crowley K., \& Knutson K. (Eds.), Learning conversations in museums (pp. 357-400). Mahwah, NJ: Erlbaum.

Ash, D. \& Brown, A.L. (1996, April). Thematic continuities guide shifts in biological reasoning: Children's transition towards deep principles of evolution. Paper presented at the annual meeting of American Educational Research Association, New York.

Ash, D. \& Klein, C. (1999). Inquiry in the informal learning environment. In Minstrell J. \& Van Zee E. (Eds.), Teaching and learning in an inquiry-based classroom (pp. 216-240). Washington, DC: American Association for the Advancement of Science.

Ash, D., Ostrenko, M., Steier, F., \& Borun, M. (2000, August). Analyzing inquiry through visitor conversation. Symposium presented at the annual meeting of the Visitor Studies Association, Boston.

Blud, L. (1990). Social interaction and learning among family groups visiting a museum. Museum Management and Curatorship, 9, 43-51.

Borun, M. \& Dritsas, J. (1997). Developing family-friendly exhibits. Curator, 40, 178-196.

Brown, A.L. (1992). Design experiments: Theoretical and methodical challenges in creating complex interventions in classroom settings. Journal of Learning Sciences, 2, 141-178.

Brown, A.L., Ash, D., Rutherford, M., Nakagawa, K., Gordon A., \& Campione, J.C. (1993). Distributed expertise in the classroom. In Salomon G. (Ed.), Distributed cognitions: Psychological and educational considerations (pp. 188-228). New York: Cambridge University Press.

Brown, A.L. \& Campione, J.C. (1994). Guided discovery in a community of learners. In McGilly K. (Ed.). Classroom lessons: Integrating cognitive theory and classroom practice (pp. 229-270). Cambridge, MA: MIT Press.

Brown, A.L. \& Campione, J.C. (1996). Psychological theory and the design of learning environments: On procedures, principles and systems. In Schauble L. \& Glaser R. (Eds.), Innovations in learning: New environments for education (pp. 289-325). Mahwah, NJ: Erlbaum.

Brown, A.L., Campione, J., Metz, K., \& Ash, D. (1998). The development of science learning abilities in children. In Burgen A. \& Harnquist K. (Eds.), Growing up with science: Developing early understanding of science (pp. 156-178). Dordrecht, The Netherlands: Kluwer Academic.

Brown, A.L., Ellery, S., \& Campione, J.C. (1997). Creating zones of proximal development electronically. In Green J. \& Goldman S. (Eds.), Thinking practices in math and science education (pp. 149-214). Hillsdale, NJ: Erlbaum. 
Carey, S. (1985). Conceptual change in childhood. Cambridge, MA: MIT Press.

Crowley, K. \& Callanan, M. (1998). Describing and supporting collaborative scientific thinking in parent-child interactions. Journal of Museum Education, 23, 12-17.

Crowley, K. \& Galco, J. (1999). Everyday activity and the development of scientific thinking. In Crowley K., Schunn C.D., \& Okada T. (Eds.), Designing for science: Implications from everyday classrooms and professional settings (pp. 123-156). Mahwah, NJ: Erlbaum.

Diamond, J. (1986). The behavior of family groups in science museums. Curator, 29, 139-154.

Diamond, J. (1999). Practical evaluation guide: Tools for museums and other informal educational settings. Walnut Creek, CA: Alta Mira.

Dierking, L.D. (1987). Parent-child interactions in free-choice learning settings: An examination of attention-directing behaviors. Dissertation Abstracts International, 49, 778A.

Dierking, L.D. (1989). The family museum experience: Implications from research. Journal of Museum Education, 14, 9-11.

Dierking, L.D. \& Pollack, W. (1998). Questioning assumptions: An introduction to front-end studies in museums. Washington, DC: Association of Science and Technology Centers.

Driver, R., Leach, J., Millar, R., \& Scott, P. (1996). Young people's images of science. Philadelphia, PA: Open University Press.

Edwards, D. \& Mercer, N. (1987). Common knowledge. London: Methuen/Routledge.

Ellenbogen, K. (2000, April). Using museums: An ethnographic case study. Paper presented at the American Educational Research Association annual meeting, New Orleans.

Ellenbogen, K.M. (2002). Museums in family life: An ethnographic case study. In Leinhardt G., Crowley K., \& Knutson K. (Eds.), Learning conversations in museums. Mahwah, NJ: Erlbaum.

Falk, J. \& Dierking, L. (1992). The visitor experience. Washington, DC: Whalesback.

Falk, J. \& Dierking, L. (2000). Learning from museums: Visitor experiences and the making of meaning. Walnut Creek, CA: Alta Mira.

Gallas, K. (1995). Talking their way into science. New York: Teacher College Press.

Gelman, S.A. \& Wellman, H.M. (1991). Insides and essences: Early understanding of the non-obvious. Cognition, 38, 213-244.

Gleason, M. \& Schauble, L. (2000). Parents' assistance of scientific reasoning. Cognition and Instruction, 17, 343-378.

Granott, N. (1998). Unit of analysis in transit: From the individual's knowledge to the ensemble process. Mind, Culture and Activity, 5, 42-66.

Halliday, M.A.K. (1993). Towards a language-based theory of learning. Linguistics and Education, 5, 93-116.

Heath, S.B. (1992). "It's about winning!" The language of knowledge in baseball. In Resnick L.B., Levine J.M., \& Teasley P. (Eds.), Perspectives on socially shared cognition (pp. 101-126). Washington, DC: American Psychological Association.

Hein, G. (1998). Learning in the museum. New York: Routledge.

Hilke, D.D. (1987). Museums as resources for family learning: Turning the question around. The Museologist, 50, 14-15.

Hilke, D.D. \& Balling, J.D. (1989). The family as a learning system: An observational study of families in museums. Washington, DC: Smithsonian Institute. $50-57$.

Hood, M. (1983). Staying away: Why people choose to visit museums. Museum News, 61,

Hood, M. (1989). Leisure criteria of family participation and nonparticipation in museums. In Butler B. \& Sussman M. (Eds.), Museum visits and activities for family life enrichment (pp. 151169). New York: Haworth. 
Inagaki, K. \& Sugiyama, K. (1988). Attributing human characteristics: Developmental changes in over- and underattribution. Cognitive Development, 3, 55-70.

Keil, F. (1992) The origins of autonomous biology. In Gunman M.R. \& Marasotos M. (Eds.), Minnesota Symposium on Child Psychology: Modularity and constraints on language and cognition (pp. 123-197). Hillsdale, NJ: Erlbaum.

Lave, J. \& Wenger, E. (1991). Situated learning: Legitimate peripheral participation. New York: Cambridge University Press.

Leinhardt, G., Crowley, K., \& Knutson, K. (2002). Learning conversation in museums. Mahwah, NJ: Erlbaum.

Lemke, J.L. (1990). Talking science: Language, learning, and values. Norwood, NJ: Ablex.

Leont'ev, A.N. (1981). The problem of activity in psychology. In Wertsch J.V. (Ed.), The concept of activity in Soviet psychology (pp. 37-71). Armonk, NY: M.E. Sharpe.

Martin, L. (1996, April). A Vygotskian approach to the design of a science center. Paper presented at the annual meeting of the American Educational Research Association, New York.

Matusov, E. \& Rogoff, B. (1995). Evidence of development from people's participation in communities of learners. In Falk J. \& Dierking L. (Eds.), Public institutions for personal learning: Establishing a research agenda (pp. 97-104). Washington, DC: American Association of Museums.

McManus, P. (1988). Good companions: More on the social determination of learning-related behaviour in a science museum. International Journal of Museum Management and Curatorship, 7, 37-44.

McManus, P. (1989). What people say and how they think in a science museum In Uzzell D.L. (Ed.), Heritage Interpretation, Vol 2: The visitor experience (pp. 156-165). London: Bellhaven.

McManus, P. (1994). Families in museums. In Miks L. \& Zavala A. (Eds.), Towards the museum of the future (pp. 81-118). London: Routledge.

Medin, D. \& Ortony, A. (1989). Comments on part I: Psychological essentialism. In Vosniadou S. \& Ortony A. (Eds.), Similarity and analogical reasoning (pp. 89-103). Cambridge, MA: Cambridge University Press.

Metz, K. (1995). Reassessment of developmental constraints on children's science instruction. Review of Educational Research, 65, 93-127.

Nassaji, H. \& Wells, G. (2000). What's the use of triadic dialogue? An investigation of teacher-student interaction. Applied Linguistics, 21, 376-406.

Newman, D., Griffin, P., \& Cole, M. (1989). The construction zone. Cambridge: Cambridge University Press.

Paris, S.G. \& Ash, D. (2002). Reciprocal theory building inside and outside museums. Curator, 43, 199-210.

Paris, S.G. \& Hapgood, S. (2002). Children's learning with objects in informal learning environments. In Paris S. (Ed.), Perspectives on object-centered learning in museums (pp. 37-54). Mahwah, NJ: Erlbaum.

Rankin, L. \& Ash, D. (1999). Opening up the black box of inquiry. Exploratorium Institute for Inquiry document. Submitted for publication.

Roberts, L. (1997). From knowledge to narrative: Educators and the changing museum. Washington, DC: Smithsonian Institution.

Rogoff, B. (1995). Observing sociocultural activity on three planes: Participatory appropriation, guided participation, and apprenticeship. In Wertsch J.V., del Rio P., \& Alvarez A. (Eds.), Sociocultural studies of mind (pp. 139-164). Cambridge: Cambridge University Press. 
Rogoff, B. (1998). Cognition as a collaborative process. In Damon W., Kuhn D., \& Siegler R.S. (Eds.), Handbook of child psychology: Cognition, perception and language, vol. 2 (pp. 679744). New York: Wiley.

Rosebery, A., Warren, B., \& Conant, F. (1992). Appropriating scientific discourse: Findings from language minority classrooms. Journal of the Learning Sciences, 2, 61-94.

Rosengren, K.S., Gelman, S.A., Kalish, C.W., \& McCormick, M. (1991). As time goes by: Children's early understanding of growth in animals. Child Development, 62, 1302-1320.

Sinclair, J.M. \& Coulthard, M.C. (1975). Towards an analysis of discourse: The English used by teachers and pupils. London: Oxford University Press.

Stevens, R. \& Hall, R. (1997). Seeing tornado: How video traces mediate visitor understandings of (natural?) phenomena in a science museum. Science Education, 81, 735-748.

Tunnicliffe, S.D. (1996). Conversations with primary school parties visiting animal specimens in a museum and zoo. Journal of Biological Education, 30, 130-141.

Vygotsky, L.S. (1934/1987). Thinking and speech. In Rieber R.W. \& Carton A.S. (Eds.), The collected works of L.S. Vygotsky, Vol. 1: Problems of general psychology. New York: Plenum.

Vygotsky, L.S. (1978). Mind in society: The development of higher psychological processes. Cambridge, MA: Harvard University Press.

Wells, G. (1997). A sociocultural perspective on classroom discourse: Appendix A. Coding scheme for the analysis of classroom discourse. In Davies B. \& Corson D. (Eds.), The encyclopedia of language and education, Vol. 3: Oral discourse and education (pp. 3-5). Dordrecht, The Netherlands: Kluwer Academic.

Wells, G. (1999). Dialogic inquiry: Towards a sociocultural practice and theory of education. New York: Cambridge University Press.

Wells, G. (Ed.). (2000). Action, talk, and text: Learning and teaching through inquiry. New York: Teachers College Press.

Wertsch, J. (1991). Voices of the mind: A sociocultural approach to mediated action. Cambridge, MA: Harvard University Press.

Wertsch, J. (1998). Mind as action. New York: Oxford University Press.

White, B. (1993) Intermediate causal models: A missing link for successful science education. In Glaser R. (Ed.). Advances in instructional psychology (pp. 177-252). Hillsdale, NJ: Erlbaum. 